\title{
Pragmatismo e os pragmáticos nos estudos organizacionais
}

\section{Pragmatism and the pragmatics in organizational studies}

\author{
Francis Kanashiro Meneghetti ${ }^{1}$
}

\section{Resumo}

O objetivo central deste ensaio teórico é avaliar as contribuições do pragmatismo nos Estudos Organizacionais e, os específicos, avaliar se as contribuições teóricas de Charles Peirce e John Dewey possibilitam afirmar o pragmatismo como senso comum, ciência ou teoria do conhecimento; analisar as contribuições - possibilidades e limites - do pragmatismo como conhecimento científico; compreender os percursos do pragmatismo nos Estudos Organizacionais. Chega-se $\dot{a}$ conclusão de que ser pragmático é diferente de conceber estudos articulados no campo epistemológico do pragmatismo. O sujeito pragmático vê na sua utilidade e na necessidade de ação, o ponto de tensão que coloca em dúvida a veracidade dos pressupostos do pragmatismo como ciência. O que ocorre nos Estudos Organizacionais éa conversão do pragmatismo como conhecimento científico em subordinação irracional à utilidade e à ação prática, sobretudo, no campo da economia, da política, da ciência, da cultura, da educação, e assim por diante.

Palavras-chave: Pragmatismo; Estudos Organizacionais

\begin{abstract}
The main objective of this theoretical essay is to analyze the main contributions that Pragmatism has offered to Organizational Studies and, more specifically, evaluate whether the theoretical contributions by such philosophers as Charles Pierce and John Dewey allow us to regard pragmatism as common sense, science, or theory of knowledge. This paper also examines the contributions - possibilities and limitations - of pragmatism as scientific knowledge in order to understand the path of pragmatism in Organizational Studies. The likely conclusion is that to be pragmatic is not to conceive of studies articulated in the epistemological field of pragmatism. The pragmatic individual sees in the usefulness and in the need for action the tension point that casts a doubt in the veracity of the assumptions of pragmatism as a science. What takes place in Organizational Studies is the conversion of pragmatism as scientific knowledge into irrational subordination to function and practical action, mainly in the fields of economy, politics, science, culture, education, and so on.
\end{abstract}

Keywords: Pragmatism; Organizational Studies

\footnotetext{
1 Administrador, Mestre em Administração e Doutorando em Educação pela UFPR/Unibrasil. Endereço: R. Konrad Adenauer 442 - Tarumã - Curitiba-PR. Cep: 82.820-540 - Email: f.meneghetti@terra.com.br

Artigo recebido em julho de 2006 e aceito para publicação em setembro de 2006
} 


\section{Introdução}

O importante para o pragmatismo é definir, logo de início, um plano de ação baseado em algumas utilidades. Dessa forma, o objetivo central deste artigo é avaliar as contribuições do pragmatismo nos estudos organizacionais e, especificamente, avaliar se as contribuições teóricas de Charles Pierce e John Dewey possibilitam afirmar o pragmatismo como senso comum, ciência ou teoria do conhecimento, analisar suas contribuições (possibilidades e limites) como conhecimento científico e compreender seus caminhos nos estudos organizacionais. Como resultado desse processo, chega-se à conclusão de que ser pragmático é diferente de conceber estudos articulados no campo epistemológico do pragmatismo.

Definidos os elementos orientadores desta análise, é proposta uma reflexão sobre o tema em relação aos seus pressupostos como conhecimento, ao mesmo tempo em que se tem a pretensão de ser, para os pragmáticos dos estudos organizacionais, uma chamada para a reflexão, pois são eles que subvertem seus pressupostos científicos.

\section{Pierce e Dewey e a centralidade da ação e do útil}

O pragmatismo é entendido como uma doutrina em que as idéias são instrumentos da ação; isto é, só têm utilidade quando produzem efeitos práticos. Sua força está, particularmente, na aplicação prática; ou seja, na idéia que se consolida em ação. Assim, a verdade para o pragmático é só aquilo que se concretiza como ação. Desse modo, é estabelecida uma oposição ao intelectualismo e, mais do que isso, uma redução do mesmo às instâncias das atitudes utilitárias e de ações concretas.

Essa visão que questiona a importância do intelectualismo vai contra a concepção de Marx ao afirmar que o conhecimento pode ser revolucionário, pois muitas vezes é o momento da aproximação da consciência com o real, mais especificamente com a compreensão sistematizada da realidade. Dessa forma, não é em vão que Marx afirma que a diferença entre o pior dos arquitetos e a mais habilidosa das abelhas é a capacidade deles de imaginar o que irão realizar. Apesar dessa oposição clara de Marx em relação à importância do intelectualismo, o pragmatismo tem importância singular para a compreensão da realidade e de sua transformação.

Assim, vários são os teóricos que contribuíram para sua construção como conhecimento científico. Entre os mais representativos estão os já citados Charles Pierce e John Dewey, além de George Herbert Mead e William James nos EUA, Ferdinand Schiller na Inglaterra, Hans Vaihinger na Alemanha, Miguel de Unamuno na Espanha e Giovanni Papini, Giuseppe Prezzolini, Giovanni Vailati e Mario Calderoni na Itália. Cada um deles presta significativa contribuição na sua construção ou consolidação como conhecimento. Para evitar equívocos conceituais causados pelo descuido no rigor analítico necessário ao entendimento de qualquer conhecimento específico, serão abordadas contribuições de Pierce e Dewey.

A compreensão do senso comum quanto ao pragmatismo revela apenas uma parte do entendimento científico possível e necessário. James atribui a Pierce a origem do pragmatismo, surgido nos EUA em meados do século XIX, com presença explicitamente significativa até a segunda década do século XX. É considerado por muitos, vertente lógica do utilitarismo (a verdade é medida pela sua utilidade) e herdeiro do empirismo inglês. Bacon, Locke, Berkeley e Hume consideravam a experiência acumulação e organização progressiva de sensíveis dados passados e futuros (REALE e ANTISERI, 1991, p.485), fonte do conhecimento. Já o pragmatismo tem na experiência o principal elemento de orientação do futuro e norma da ação. Surge, basicamente, num período de expansão econômica norte-americana e caracteriza-se historicamente pelo descrédito no fatalismo e na certeza de que só a ação, por meio da inteligência e energia, é capaz de alterar os limites da condição humana.

O pragmatismo surge, portanto, em um contexto histórico específico dos EUA e, para justificar a ação como ato de primazia, orienta, filosoficamente (termo aqui utilizado mais no sentido de conjunto de idéias), um arcabouço de natureza ideológica que fundamenta os fatos ocorridos na dimensão econômica, política e cultural. Esse arcabouço desenvolve-se atualmente com intensidade nas decisões e ações dos sujeitos na América do Norte e, também, em grande parte da Europa. Não é exagero afirmar que o crédito depositado no neoliberalis- 
mo só se efetiva em razão das condições materiais organizadas na polarização entre capital e trabalho, reforçada por sujeitos que agem pragmaticamente por acreditarem na eqüidade econômica futura, ou, em alguns casos, por indivíduos que já assumiram sua posição de aceitar as diversas formas de banalização decorrentes das diferenças econômicas promovidas por esse sistema econômico e político.

Pierce (1989) foi o construtor do pragmatismo como ciência. Para ele, conhecimento é essencialmente pesquisa e, mais do que isso, pesquisa direcionada para ação. A origem está na dúvida, mais especificamente na "irritação" que o pesquisador sente dessa dúvida. A partir disso, surgem as crenças, hábitos determinantes das nossas ações. Da dúvida à crença (PIERCE, 1877), o autor fundamenta que, para se chegar ao método de fixação da crença, quatro etapas se apresentam:

- método da tenacidade - é o exemplo do avestruz que se esconde da realidade. É a postura de quem está diante da realidade. A insegurança ocorre, quando o pesquisador se defronta com outras crenças tidas como igualmente "boas" por outros;

- método da autoridade - é o método das crenças organizadas. A partir da ignorância, procura-se conseguir a concordância daqueles que não aderem às suas explicações. É a busca pela harmonia. Pierce afirma que nenhuma crença é eterna, pois a história redimensiona sua posição e a particulariza em determinado momento.

- método do a priori - é a posição atribuída às próprias proposições elementares, conforme uma razão. Tal método leva ao fracasso, pois a razão de um não é, necessariamente, a razão dos outros;

- método científico - ao contrário dos outros três métodos, este é o correto. Na ciência, há três formas diferenciadas de raciocínio: a dedução, a indução e a abdução. A dedução parte do específico para o geral. A indução, do particular para o específico (classifica, mas não explica) (PIERCE, 1878). A abdução (e aqui repousa a contribuição de Pierce) fornece um tipo de raciocínio que, para chegar à explicação de um fato problemático, necessita inventar uma hipótese (conjectura) da qual sejam deduzidas consequiências que, obviamente, possam ser verificadas indutivamente (experimentalmente).

A abdução proposta por Pierce demonstra que as crenças científicas são sempre falíveis, porque as provas obtidas por meio dos experimentos sempre desmentem as consequiências das hipóteses (conjecturas).

Assim, o método científico, cujo princípio consiste em formular hipóteses e submetê-las à verificação, analisando suas consequiências, é o método válido. A partir dessas considerações, Pierce (1879) elabora a teoria do significado que, posteriormente, fundamentará a construção de uma teoria dos sinais - a semiótica. $\mathrm{O}$ conceito, como

[...] significado racional de uma palavra ou de outra expressão, consiste exclusivamente em seus concebiveis reflexos no transcorrer da vida, de modo que, obviamente, nada daquilo que não possa resultar do experimento pode ter qualquer reflexo direto sobre esta. Desse modo, se alguém pode definir acuradamente todos os fenômenos experimentais concebíveis que a afirmação ou negação de um conceito pode implicar, terá conseqüentemente, uma definição completa do conceito - e nele não há absolutamente mais nada. (PIERCE, 1879, p.42)

Dessa forma, todo conceito se reduz aos efeitos experimentais concebíveis do objeto, que como tal é constantemente submetido às provas experimentais. Por isso, sempre possibilita múltiplas concepções, pela variedade de suas ações sobre os sentidos dos sujeitos. Portanto, um conceito se reduz aos seus efeitos experimentais concebíveis, os quais reduzem as ações possíveis; ações efetuáveis no momento. Um exemplo disso é o conceito de água, o qual se reduz aos efeitos controláveis, que, por sua vez, nas oportunidades de identificação desse objeto (água), levam a certos tipo de comportamento adequados às qualidades que acredita-se que a água tenha. Assim, as crenças são normas de ações possíveis.

Para Pierce o conhecimento sobre algo não é intuição (PIERCE, 1877), síntese a priori (clara referência de oposição à concepção kantiana) ou percepção do senso comum. É pesquisa com origem no estado de dúvida até chegar ao estado de crença. 
O pragmatismo de Pierce não adere meramente a verdade à utilidade, mas estrutura-se na lógica da pesquisa ou na norma metodológica que vê a verdade como entendimento por se fazer. Dessa forma, a verdade jaz no futuro e nunca é definitiva. O pragmatismo de Pierce é empirismo, mas diferente do empirismo clássico inglês, voltase para o futuro na construção do conhecimento. Não poderia ser diferente, pois toda ação é partir de algo para realizar algo, ir de um ponto de partida até um ponto de chegada. A lógica do conhecimento repousa, por conseguinte, no movimento. Observa-se que crença é algo que se conhece por um conjunto de percepções a respeito de algo em determinado tempo. Crença essa que não é o objeto, mas representação dele no contexto da ação.

A experiência não se reduz à consciência, tampouco ao conhecimento. Essa concepção de Dewey sustenta bem os limites da experiência. Considerado um "naturalista", tem na teoria da evolução das espécies de Charles Darwin um dos seus principais pressupostos teóricos. Concebe sua filosofia como instrumentalismo, que, de início, diferencia-se do empirismo clássico em relação ao entendimento do que é experiência. Dewey (1929, p.38) fundamenta que a experiência não é consciência, mas sim história (que tem como fundamento o movimento).

A experiência é algo completamente diverso da "consciência", que é aquilo que aparece qualitativa e focalmente em momento particular. O homem comum não tem necessidade de que lhe recordem que a ignorância é um dos principais aspectos da experiência e que tais são os hábitos que abandonamos sem consciência, tão hábil e seguro é o modo como eles se dão. Entretanto, a ignorância, o hábito e o radicar-se fatal no passado são precisamente as coisas que o chamado empirismo nega à experiência quando a reduz a estados de consciência.

Dessa forma, o problema gnosiológico (também conhecido como teoria do conhecimento) é um conflito entre a experiência e o conhecimento. Esse "é o problema de como encontrar o que é necessário encontrar em torno dessas coisas para garantir, retificar ou evitar o tê-las ou o sê-las." (DEWEY apud REALE e ANTISERI, 1991, p.505). Assim, o conhecimento é processo de investigação (avanço por tentativas de solução), tanto quanto meio de adaptação ao ambiente. Conhecer é fazer. Há continuidade entre conhecimento comum e conhecimento científico.

O instrumentalismo de Dewey tem como premissa um entendimento contrário ao da filosofia tradicional, que atribui à verdade caráter estático, definitivo, absoluto, eterno e imutável. Contrário à filosofia tradicional, compreende que o processo de evolução (na acepção darwinista) é o elemento primordial no processo de investigação. O conhecimento, portanto, é prática que procura resolver e compreender o ambiente.

A investigação é "a transformação controlada ou direta de situações indeterminadas em situação determinada em suas distinções e relações constitutivas, a ponto de converter os elementos da situação originária em totalidade unificada." (DEWEY apud REALE e ANTISERI, 1991, p.508). Assim, o significado de instrumentalismo passa pela compreensão de que a verdade é a adequação do pensamento ao ser - o critério da verdade é o êxito prático, mas identificação (aqui, também me falta uma palavra) com a comprovação de uma idéia, a partir de um corpo sempre crescente das afirmações garantidas. Essas garantias, contudo, não são absolutas e imutáveis, pois a história é a medida da experiência que as constrói. As idéias são apenas planos de operações e intervenções na realidade existente. Não podem ser verdadeiros ou falsos, mas eficazes ou inúteis.

A concepção de Dewey sobre a realidade passa pela idéia de uma totalidade composta de elementos práticos, que por sua vez formam um conjunto de "regras" não-absolutas, mas relativas, pois podem ser modificadas pela ação orientada por "instrumentos".

Das contribuições temáticas mais significativas de Dewey, a educação e a democracia ganharam destaque especial. Com a expectativa de desenvolver uma sociedade melhor por meio de uma educação progressista, as escolas deveriam ser refeitas e tidas como microcosmos da sociedade, orientadas sempre para a ação e a prática. A ciência, no contexto da educação, deve chegar ao aluno pela prática. Em uma sociedade industrial, na sua concepção, a escola precisa ser uma oficina, uma comunidade em miniatura (DEWEY, 1936). Necessita orientar pela tentativa e erro as disciplinas necessárias ao estabelecimento da ordem econômica e social. Destarte, cabe à escola educar instruindo, uma vez que ela é um microcosmo da sociedade. 
Essa visão do que seja educação mostra com clareza o entendimento que Dewey tem do ambiente e de como agir para modificá-lo. Para ele, a escola é a representação pormenorizada do que ocorre na sociedade. Essa compreensão funcionalizada é responsável por orientar grande parte da concepção norte-americana de educação. Credita aos sujeitos, ainda, a responsabilidade de agir, de serem os responsáveis por suas próprias escolhas e, conseqüentemente, por seus destinos. Não percebe as contradições, diferenças materiais, culturais, políticas e ideológicas de cada situação. Tal entendimento da realidade não leva em consideração, ainda, as diferenças surgidas das associações entre indivíduos e grupos. Em cada um deles, as histórias são diferentes e a realidade também. Cada grupo é composto por sujeitos com histórias diferentes e não são o somatório das experiências individuais, mas um complexo conjunto de sentimentos que percorrem o grupo de forma a dinamizá-lo.

Outro elemento importante para reflexão é a relação entre o conhecimento e a prática. A separação entre teoria e prática não se justifica, na medida em que a prática (que, em última instância, tem alguma relação com o concreto) é responsável pela construção da teoria, ao mesmo tempo em que, dialeticamente, a teoria influencia e faz parte da construção da prática como ação orientadora.

Analisando pela ótica da concepção de Dewey, o instrumentalismo não exige, necessariamente, uma versão meramente prática. A teoria, tal como a matemática, a física e as demais ciências da lógica, é exemplo tanto quanto os modelos matemáticos e físicos - orientados em ações específicas para realização de objetivos concretos - são instrumentos de orientação para ações que causam (posteriormente à sua aplicação) resultados concretos.

Não se pretende esgotar as constituições que Pierce e Dewey revelam, mas é importante salientar que ambos são importantes na concepção do pragmatismo Suas observações e apontamentos, assim como suas reflexões, surgiram da sua realidade para se tornarem conhecimento visando esclarecer, sem o propósito de dogmatizar.

\section{Pragmatismo: senso comum? Ciência? Teoria do conhecimento?}

O termo senso comum tem conotação pejorativa entre os acadêmicos, seja nas ciências ou na filosofia. De fato, está associado à ignorância, ao entendimento massificado da realidade, àquilo que é tangível por todos; enfim, a uma compreensão da realidade generalizada, quase sempre sem reflexão e preconceituosa. Todavia, o caráter prático do senso comum é o de fornecedor de esquemas de compreensão da realidade, capaz de criar imaginários e "realidades", agregando indivíduos, os quais, portanto, se tornam responsáveis por estabelecer "razões" e vínculos comuns que agregam e mantêm o controle social.

O pragmatismo, como não podia ser diferente, concebe o senso comum como algo útil, desde que associado ao caráter prático e motivador da ação. É dessa forma que se justifica a afirmação de Dewey ressaltando o caráter prático do senso comum:

[...] visto que os problemas e as indagações em torno do senso comum dizem respeito às interações entre os seres vivos e o ambiente, com o fim de realizar objetos de uso e de fruição, os símbolos empregados são determinados pela cultura corrente de um grupo social. Eles formam um sistema, mas tratase de um sistema de caráter mais prático que intelectual. Esse sistema é constituído por tradições, profissões, técnicas, interesses e instituições que são efeito da linguagem cotidiana comum, com a qual os membros do grupo se intercomunicam. (DEWEY, 1949, p.170)

Para ele, o que importa é sua capacidade prática de integrar indivíduos à ação prática, permitindo fugir do intelectualismo. A suposta renúncia ao intelectualismo deve-se à oposição clara dos filósofos norte-americanos ao velho continente, na sua época, procurando reafirmar a necessidade da prática, por meio da ação dirigida e controlada para um fim, como guia de uma nação. Nesse contexto, o senso comum é a opção clara que norteia as ações da população. $\mathrm{O}$ fundamento, que justifica ideologicamente as ações em prol de um objetivo, faz do cálculo da eficiência o medidor almejado pela nova ciência, o pragmatismo.

Contudo, há distinção entre o conceito de senso comum da época e o da atualidade. Enquanto o conceito associado ao pragmatismo se baseia na ignorância por não conhecer, o da atualidade está muito mais ligado à renúncia ao conhecimento, o que os diferencia muito. O senso comum do pragmatismo não nega a procura por 
algumas formas de compreensão da realidade, apenas a associa à natureza prática da vida. $\mathrm{O}$ senso comum de hoje é a ignorância alimentada pela indústria cultural, responsável por massificar o conhecimento e alinhavar opiniões sobre um mesmo tema. É a embriaguez relacionada com o excesso de informação que nada explica, com a uniformização da crítica vendida pelos colunistas de jornais ou comentaristas da economia, da política, da cultura, da moda (afinal, de tudo) como verdade.

A questão central na discussão do senso comum está na relação entre teoria e prática. A relação entre ambas cuja sentença de separação foi formalizada pelos filósofos modernos com o problema da relação sujeito/objeto - tem singular espaço no "teatro" da suposta pós-modernidade. "Teatro" porque os próprios pós-modernos estabelecem uma separação entre teoria e prática que não existe, e alguns mais extremistas ainda afirmam que a teoria nunca existiu. Dessa forma, transformam todas as discussões em encenações, no palco do relativismo. $\mathrm{O}$ que piora o embate é a recusa à leitura de alguns autores - Vázquez (1977) é um deles - pelo simples fato de acreditarem na morte do marxismo e mesmo de outras ciências fundamentadas em epistemologias diferentes.

Diferente dos pós-modernos, o pragmatismo faz da prática sua primazia, mas não recusa completamente a teoria, colocando-a, porém, numa posição secundária. Se bem que quase sem expressão ou utilidade, desde que a teoria possa ser a engrenagem do útil e do prático, terá seu valor de ação. Como afirma Vázquez (1977, p. 211),

[...] a história do pensamento filosófico mostra também um modo de conceber as relações entre teoria e prática sob uma forma que não passa do ponto de vista do senso comum, depurado de seu aspecto rudimentar, e alcança o nível de doutrina filosófica: tal é o ponto de vista do pragmatismo. Seu praticismo se põe em evidência, principalmente, em sua concepção da verdade; do fato de nosso conhecimento infere que o verdadeiro se reduz ao útil, com o que solapa a própria essência do conhecimento.

Essa visão de Vázquez leva a outra reflexão, que coloca no centro da discussão duas outras categorias: a verdade e o conhecimento.

Conforme James (2005) questiona, o que é verdade e como se diferencia do erro? Essa pergunta fundamental no pragmatismo é proposta para elaborar atitudes filosóficas que justifiquem as sucessivas descobertas científicas, no final do século XIX. A verdade, relacionada ao que pode ser conhecido, só é efetiva quando útil. Assim, o que é verdadeiro é o que é útil. Não há erro na verdade que parte da utilidade, pois essa é a medida de todas as coisas, é guia da ação.

Contrário a essa concepção, Vázquez (1977, p.213) entende que

O conhecimento é útil na medida em que é verdadeiro, e não, inversamente, verdadeiro porque é útil, como afirma o pragmatismo. Enquanto para o marxismo a utilidade é conseqüência da verdade, e não seu fundamento ou essência, para o pragmatismo a verdade fica subordinada à utilidade, entendida esta como eficácia ou êxito da ação do homem, concebida esta última, por sua vez, como ação subjeti$v a$, individual, e não como atividade material, objetiva, transformadora.

A oposição evidente direciona a reflexão sobre a verdade e o conhecimento para a compreensão da ação humana. Nem toda ação individual, de natureza subjetiva, é verdade, pois os critérios de utilidade da mesma variam conforme o contexto social e sua história. Além disso, é a realidade concreta que define o que é utilidade e não o inverso. Não é possível falar em ação sem os limites da realidade, e esta por sua vez tem correspondência com o mundo material, objetivo e contraditório, ao mesmo tempo.

A discussão sobre a verdade sempre ocorreu no âmbito da ciência. A verdade, portanto, direta ou indiretamente é categoria que fundamenta qualquer concepção de ciência. Construindo entendimentos específicos para cada época, o acesso à verdade, para os racionalistas, está na razão; para os empiristas, na experiência; e, para os pragmáticos, na utilidade. A ciência moderna, formada desde os pensadores racionalistas, passando pelos empiristas e positivistas, é entendida como conhecimento confirmado qualitativa e/ou quantitativamente, com garantias de própria validade. A ciência moderna, hoje, já não tem, única e exclusivamente, a pretensão de determinar a razão como elemento central da certeza, tal como atribuído pelos racionalistas; ou de creditar a experiência à realidade, como faziam os empiristas; ou, ainda, compreender a realidade por meio de operações positivas, 
como confiavam os positivistas. O conceito de ciência aqui utilizado leva em consideração as garantias na demonstração, na descrição ou corrigibilidade, todas juntas ou isoladas.

O pragmatismo, como conhecimento, tem uma virtude, que ao mesmo tempo se torna um limite: pretende denunciar as falácias filosóficas, sobretudo de natureza consolatória ou ilusória. A efetivação da realidade pela prática exclui qualquer forma de pensamento metafísico que procura, além da realidade concreta, o alojamento da compreensão baseada na idéia ou na adesão ao mítico. Dessa perspectiva é possível afirmar que o pragmatismo tem sua validade, pois se apresenta como o primeiro elemento na constituição da consciência esclarecida.

É fato que há continuidade do conhecimento comum (senso comum) e do conhecimento científico.

A ciência, no sentido especializado, é a elaboração de operações cotidianas, ainda que essa elaboração assuma freqüentemente caráter muito técnico. [...] A ciência tem seu ponto necessário de partida nos objetos qualitativos, nos processos e nos instrumentos do senso comum, que é o mundo do uso, da fruição e dos sofrimentos concretos. (DEWEY apud REALE; ANTISERI, 1991, p.510)

Todavia, não é possível afirmar que senso comum e conhecimento tenham as mesmas propriedades. O "ponto de mutação" está em algumas características que possibilitam afirmar a validade científica do pragmatismo. São elas:

- a adoção de método nas ações de pesquisa;

- a validação de afirmações por comparações quantitativas;

- comparações qualitativas, mesmo subordinadas às regras da utilidade; e

- mudança de estado qualitativo e quantitativo da realidade e possibilidade de generalização de resultados com base em observações da realidade.

Aristóteles (2002) apresenta reflexões iniciais sobre a ciência (é evidente que o livro discute os pressupostos da ciência antiga, a qual, naturalmente, têm relação com a ciência moderna). A metafísica de Aristóteles tem como objetivo identificar, primeiro que tudo, as causas e os princípios; isto é, verificar as causas e os princípios que condicionam qualquer realidade, para identificar causas e princípios que fundamentam os seres em sua totalidade. São apresentadas quatro causas fundamentais para compreensão sistemática da realidade:

- causa formal - a forma ou essência das coisas. São as "relações" para diversas figuras geométricas (para os triângulos seria o fato de todos eles apresentarem três ângulos internos);

- causa material - o constituinte da coisa, ou seja, aquilo do que é feito a coisa (o ouro do anel de ouro, o mármore da estátua de mármore);

- causa eficiente - aquilo de que provém a mudança e o movimento da coisa. A vontade é a causa eficiente da ação humana, como o chute na bola é a causa eficiente do movimento da bola;

- causa final - o propósito da coisa e das ações, relacionado com a função da coisa.

Três das quatro causas são intrínsecas à coisa da qual são causas. Apenas a eficiente é externa; ou, pelo menos, distinta da coisa. Observando os pressupostos do pragmatismo e comparando-os com a teoria aristotélica da compreensão do ser (ou das coisas), é possível verificar que seus pressupostos se baseiam, principalmente, em duas das quatro causas, a eficiente e a final.

A causa final está relacionada aos pressupostos da utilidade, pois é possível identificar sempre um propósito ou um fim para alguma coisa. Para uma máquina, pressupõe-se uma atividade mais rápida ou precisa no processo de transformar alguma coisa. Para um avião, a utilidade de transportar objetos ou pessoas.

A causa eficiente está relacionada com a ação prática, pois toda causa eficiente gera mudança e/ou uma ação. Apesar disso, os pressupostos do pragmatismo não contemplam explicitamente a causa material e a formal, ocorrendo uma subordinação dessas causas à condição de eficiência e finalidade. 
Essas características possibilitam classificar o pragmatismo no campo da ciência, sobretudo, porque seguem os pressupostos científicos quase uniformemente aceitos pelas várias correntes epistemológicas. Entretanto, o pragmatismo não constitui teoria do conhecimento. A teoria do conhecimento investiga os problemas decorrentes da relação entre o sujeito e o objeto do conhecimento, bem como as condições primordiais do saber verdadeiro. Os principais problemas enumerados pela teoria do conhecimento se referem à sua veracidade, às formas de apreensão do objeto, à totalidade do conhecimento e suas fontes. A verdade (não a individual, mas a social) depende apenas dos sujeitos individuais e coletivos, ou seja, do juízo do indivíduo relacionado aos "juízos" compartilhados a partir dos fenômenos sociais. O objeto tem primazia na formação da veracidade e não o que está simplesmente no plano das idéias ou na subjetividade do pesquisador.

Pode-se fazer uma divisão didática da teoria do conhecimento, baseada nos principais problemas enfrentados por ela:

- a possibilidade;

- a origem;

- a essência;

- as formas; e

- o valor (o problema da verdade).

Essa divisão didática possibilita pensar o pragmatismo como ciência, mas não como teoria do conhecimento. Baseada nas características da ciência, a aceitação da utilidade não implica renúncia do método, das comparações quantitativas e qualitativas ou mudança de estados. Todas essas características são, não só possíveis, como são a base de sustentação da subordinação da ação a um critério de utilidade. Dessa forma, em nenhum momento a utilidade é questionada ou colocada à prova, pois, para todo objeto há uma ação que corresponda a ele ou a uma utilidade social.

Contudo, quando a discussão parte para o plano da teoria do conhecimento, a análise modifica-se, porque:

- nem toda utilidade possibilita um conhecimento;

- nem toda ação gera conhecimento;

- para conhecer a essência dos fenômenos, é necessário mais do que conhecer a utilidade do objeto ou seu efeito prático;

- as formas não são conhecidas só pelo que se pode observar na ação ou na objetividade; e

- o problema da verdade no pragmatismo é dado pela utilidade do objeto ou pela ação orientada pelo útil. Assim, a verdade subordina-se apenas a uma das dimensões possíveis para a compreensão do objeto.

De fato, o pragmatismo cumpre com as características elementares para qualificá-lo como ciência. Destarte, a ação orientada pela utilidade não empreende a construção de abstrações que ajudem a compreender a realidade sem apenas descrevê-la.

[...] não é qualquer conjunto de teses sobre um objeto qualquer que constitui uma teoria. Para se converter em teoria, o conhecimento deve atingir em seu desenvolvimento certo grau de maturidade. Quando o conhecimento compreende apenas a seleção e descrição dos fatos da realidade, relativos a esse ou àquele objeto, ele ainda não assume forma de teoria científica. A seleção e descrição dos fatos é apenas um enfoque da teoria, uma preparação para a sua criação e não a própria teoria. [...] A teoria deve compreender não só a descrição de certo conjunto de fatos, mas também sua explicação, o descobrimento das leis a que eles estão subordinados. (KOPNIN, 1978, p.238)

Como teoria científica, o pragmatismo apresenta-se como elementar para a compreensão da realidade. Suas próprias características o colocam no plano do entendimento dos fenômenos cotidianos, de forma a sustentar-se em uma visão de acordo com os pressupostos das ciências. Salvo isso, não pode ser compreendido como teoria 
do conhecimento, pois "toda teoria do conhecimento se apóia, implícita ou explicitamente, sobre uma determinada teoria da realidade e pressupõe uma determinada concepção da realidade mesma". (KOSIK, 2002, p.33)

\section{0 pragmatismo na atualidade: reflexões críticas}

A abordagem de senso comum em relação ao pragmatismo é sedutora, pois requalifica as idéias comuns no plano da sistematização com base na compreensão da utilidade e da ação prática. Em tempos de relativização das certezas científicas, o pragmatismo é um "lugar" seguro para compreensão da realidade, pois seus pressupostos científicos estão atrelados às generalizações, a partir das observações qualitativas e/ou quantitativas. Além disso, é um método que vislumbra a compreensão das diversas dimensões da vida social: a política, a ciência, a moral, a ética, a matemática, a economia, a cultura, o conhecimento; enfim, tudo que pertença ao mundo das relações sociais.

Entre os críticos do pragmatismo, Horkheimer se destaca. No sistema de produção capitalista, a ciência é, freqüentemente, meio de produção. Com finalidade utilitarista, e não com um fim em si mesmo, a ciência pragmática é a face ideológica que, ao mesmo tempo em que nega a teoria, a utiliza para o avanço do sistema que a financia. A negação da teoria é, portanto, a negação de uma reflexão mais radical sobre os "produtos" gerados por essa ciência, ao mesmo tempo em que se prevalece da sua utilização, quando orienta uma ação para fins específicos. Não é por acaso que Horkheimer (1977, p.15) faz considerações pertinentes entre a ciência e a crise, mais pontualmente sobre uma teoria pragmatista do conhecimento como formulação específica da ciência como meio de produção.

Além disso, "o conceito pragmatista de verdade, em sua exclusividade, desde que não seja completado por nenhuma metafísica contrária, corresponde à ilimitada confiança no mundo existente" (HORKHEIMER, 1990, p.156), mundo esse que é concebido pelo conjunto das ações práticas.

Um fator importante é a substituição da compreensão da realidade mediante a lógica por um sistema de elementos formais que justificam entendê-la em um universo probabilístico. "Desde o seu início o pragmatismo justificou implicitamente a atual substituição da lógica da verdade pela lógica da probabilidade, que se tornou amplamente predominante." (HORKHEIMER, 2000, p.50). O cálculo é a estrutura que justifica e ampara a compreensão de algo. A previsão por probabilidade é um dos fatores elementares para o pragmatismo. A quantidade direciona a ação, pois reduz o erro e redimensiona a ação conforme a lógica da utilidade. Nesse sentido, o pragmatismo prega "a previsão como a essência não só do cálculo, mas de todo pensamento como tal." (HORKHEIMER, 2000, p.51)

Assim, o pragmatismo não é só entendido como um método ou uma concepção de ciência, mas como uma filosofia que direciona as ações humanas, sobretudo, relacionada à prática da vida social. Essa suposta filosofia pragmática é tida como verdadeira, pois só ela atinge todas as camadas sociais e é ela que orienta a ação social de forma "correta" e para a satisfação de todos. A redução do erro por cálculo probabilístico torna a filosofia pragmática a incorporação da realidade como vivenciada pelas pessoas "comuns" e das necessidades manifestadas na vida cotidiana.

Os pressupostos da filosofia pragmatista incorporam a lógica de uma realidade que originou sua concepção. Desde as origens da ciência moderna, as formas, os métodos, as metodologias - enfim, tudo que qualifica um conhecimento como científico - são incorporados e agregados como pertencentes à filosofia pragmática, desde que esses elementos estejam ligados diretamente à ação e ao emprego utilitário. Assim,

o pensamento moderno tentou extrair uma filosofia dessa visão das coisas, tal como se apresenta no pragmatismo. O centro dessa filosofia é a opinião de que uma idéia, um conceito ou uma teoria nada mais são do que um esquema ou plano de ação, e, portanto, a verdade nada mais é do que o sucesso da idéia. (HORKHEIMER, 2000, p.49)

Essa subordinação implica perda da autonomia do pragmatismo, pois quando ele perde sua utilidade, já não pertence a si mesmo. É como se houvesse um dispositivo de destruição que, ao menor sinal de renúncia à prática, não tivesse possibilidade de constituir qualquer forma de conhecimento. Esse fato deve-se a suas origens re- 
lacionadas às ciências sociais, para as quais desde as primeiras observações dos naturalistas gregos de que na natureza sempre há uma razão utilitária para que um fenômeno ocorra seus pressupostos são marcadamente ligados à realidade do movimento físico. Por isso,

o que os pragmatistas entendem por reação é de fato transferido do campo das ciências naturais para a filosofia. Seu orgulho é "pensar sobre tudo exatamente como tudo é pensado no laboratório; isto é, como uma questão de experimentação." (HORKHEIMER, 2000, p.54)

Essa concepção orientada pela necessidade e pela ação prática de intervenção da realidade gera conhecimentos em que a ciência se subordina aos fatos reais. Todavia, na história da filosofia, na ciência ou mesmo no senso comum, nem sempre o conhecimento está atrelado única e exclusivamente à ação prática ou à utilidade. Antes de tudo, porque a definição da utilidade passa pelos aspectos subjetivos do pesquisador. Não há como dissociar o que é utilidade social do que é individual, pois os desejos e as necessidades sempre se apresentam nessa definição. Não há como dissociar os aspectos objetivos dos subjetivos do pesquisador, mesmo que sua subjetividade seja em grande parte constituída pelo social.

O conhecimento gerado pela ciência pragmática é limitado à própria construção social dos seus pressupostos ou pelas particularidades de cada cientista que a utiliza. Se, por um lado, há vários elementos comuns que possibilitam falar em um conhecimento científico compartilhado, por outro, não é possível negar a "onipotência racionalizadora da descrição e mudança da realidade baseada no cálculo utilitário de consequiências".

O conhecimento é revolucionário quando o cientista ou filósofo o aproxima da sociedade. Não são os intelectuais, com suas reflexões elitistas e metafísicas, os responsáveis por levar a transformação social por meio da práxis. Nesse ponto específico, os pragmáticos são mais importantes para a mudança social do que os "revolucionários de gabinete". Conforme Marx afirma, o conhecimento científico é revolucionário, mas desde que seja acessível à sociedade. Evidente que muitas críticas podem ser feitas a Marx, inclusive de ter um conjunto de teoria acessível a poucos, mas não se pode acusá-lo de elaborar um conhecimento para as elites dominantes. Marx aproxima teoria e prática por meio da práxis, o que torna o conhecimento possível de ser compreendido pela experiência. Assim, todo e qualquer indivíduo pode ser o revolucionário do seu próprio conhecimento.

O pragmatismo ganha forças no contexto atual fazendo com que sua relação com a "indústria cultural", seu casamento com a produção e o consumo em massa e sua associação com as necessidades materiais sejam suficientes para qualificar o pragmatismo como conhecimento sedutor e necessário. Definidas as necessidades, são definidas as utilidades que se deseja consumir. Não há divórcio a curto e médio prazo, pois toda sociedade define suas relações baseadas nessa concepção.

De fato, o pragmatismo pode ser criticado, mas não é justo acusá-lo de não ter um compromisso com as transformações sociais. Sua constituição é, essencialmente, ligada à prática. Sem ela, não há motivo de continuidade como conhecimento específico.

\section{Estudos organizacionais pragmáticos e o pragmático nos estudos organizacionais: por uma conclusão}

Quando se aborda essa temática, relacionada aos limites do conhecimento do senso comum e do conhecimento científico, a discussão é intensa. De fato, o pragmatismo contribui significativamente para a instrumentalização da ciência e para a adoção da utilidade como direcionamento. Assim, o principal limite é subordinar o conhecimento abstrato às regras da utilização e da ação prática como única forma possível de intervenção na realidade. Além disso, como possibilidade, o pragmatismo parte para a ação; fato importante, quando em atividades e/ou projetos com demandas imediatas e articulação com a transformação da realidade. Dessa forma, há uma contradição que nega, mas ao mesmo tempo afirma a importância do pragmatismo como conhecimento científico.

O que se pretende fazer nessas linhas não é requalificar sua importância ou sua validade como conhecimento, mas questionar sua adoção em todas as instâncias da vida social sem uma reflexão. É nesse sentido que a compreensão dos percursos do pragmatismo nos estudos organizacionais é necessária, levando em conta os seguintes elementos: 


\section{Contexto histórico da produção científica}

Os primeiros pressupostos do pragmatismo (como se entende hoje) surgem quase que concomitantemente à revolução. Nos estudos organizacionais, não dá para dissociá-lo da lógica do capital. Sua utilização como instrumento do capital qualifica-o como ciência subordinada às demandas de mercado. Em quase todas as áreas técnicas da administração - levando em consideração a proximidade entre técnica e necessidade de mercado - não é possível declarar a independência do pragmatismo como ciência.

\section{Interesses dominantes da época}

Não há uma única ciência ou conhecimento que não tenha vínculo político com algum grupo ou corrente de pensamento. Essa neutralidade científica não é possível, pois, conforme Marx afirma, todo conhecimento é formado pelas idéias dominantes de um determinado grupo. Naturalmente, as idéias dominantes de cada época são as idéias dominantes da elite. Não se trata de qualificar como correto ou não a aceitação ou a vinculação política ou ideológica a esse ou àquele grupo, trata-se de compreender que todos os pressupostos ou fundamentos científicos expressam a manifestação de necessidades, de racionalizações, desejos, constituições materiais ou imaginários decorrentes das relações sociais. Não seria diferente com o pragmatismo.

\section{Práticas comuns na realidade das organizações}

As organizações capitalistas - ou aquelas que não o são, mas seguem as regras de mercado - vivenciam experiências comuns, repetidas cotidianamente. Dos problemas ligados à área financeira aos de ordem comportamental dos indivíduos, são práticas subordinadas às regras do mercado, ao lucro. Assim, a importância das organizações capitalistas aparece em células que movimentam e reproduzem as necessidades, as ações e as utilidades tidas como fundamentais para a reprodução do sistema como um todo. Dessa forma, nesse modelo de sistema econômico, a utilidade aparece como um dos importantes mecanismos de orientação e controle na reprodução das práticas organizacionais.

\section{Contradições inerentes às conseqüências das ações práticas no cotidiano dos sujeitos organizacionais}

A realidade é contraditória. Por isso, as utilidades também o são, uma vez que nem sempre o útil para alguém o é para outro. Da mesma forma, em relação à ação prática, não há como dissociar o teórico do prático, pois os homens, nas suas relações sociais, definem as necessidades de sua época. Os indivíduos, transformados em sujeitos na sua coletividade, são seres dotados de necessidades diversas e contraditórias. As ações práticas do cotidiano organizacional não podem ser qualificadas, o tempo todo, como alicerces de ações pragmáticas. Os indivíduos nem sempre agem sem que haja um processo de interação da teoria com a prática - aquilo que Vázquez (1977) chama da práxis. Nem toda ação é só prática, assim como nem toda teoria é só abstração.

A avaliação dos percursos do pragmatismo requer, ainda, compreender o desenvolvimento econômico e social no momento em que ele surge como conhecimento científico e no momento em que suas características e conseqüências são analisadas. No "mundo administrado" não há como deixar de analisar a importância dos aspectos econômicos e sociais. Os estudos organizacionais, na sua versão atual, manifestam exatamente o que ocorre no plano social. Muitos estudos visam propor "soluções" para problemas organizacionais (normalmente relacionados com a eficiência e a eficácia do planejamento, do controle, da organização e da direção), sem que sejam esclarecidos os interesses que estão por trás desses estudos. Não há administração moderna sem a incorporação de uma racionalização constitutiva, também em noções de utilidade e de ação social, pois estas fazem parte da própria realidade. O que se pretende é desvencilhá-las da posição de "senhoras" que guiam e orientam toda prática organizacional.

Por fim, releva-se a postura do pesquisador da área organizacional. Ser pragmático é diferente de conceber estudos articulados no campo epistemológico do pragmatismo. O sujeito pragmático vê na sua utilidade e na necessidade de ação, o ponto de tensão que coloca em dúvida a veracidade dos pressupostos do pragmatismo como ciência. O que ocorre nos estudos organizacionais é a conversão do pragmatismo como conhecimento científico em subordinação irracional à utilidade e à ação prática no campo da economia, da política, da ciência, da cultura, da educação, e assim por diante. 
A crescente necessidade de produção científica em quantidade ou para obter vantagens diretamente relacionadas a algum tipo de ganho (principalmente material na era do capitalismo) é um dos problemas que precisam ser revistos. A massificação da produção científica e dos seus instrumentos de divulgação são importantes definidores das ações coletivas e individuais. O pragmatismo não pode e nem deve fazer do estudo no seu campo de conhecimento um instrumento utilitário do pragmático dos estudos organizacionais. Por isso, o pragmatismo dever ser preservado antes que um pragmático o destrua. 


\section{Referências}

ARISTÓTELES. Metafisica. São Paulo: Edições Loyola, 2002.

DEWEY, J. Experience and nature. New York: W. W. Norton \& Company, 1929. Democracia e educação: breve tratado de filosofia de educação. São Paulo: Nacional, 1936. Logica: teoria dell'indagine. Torino: Giulio Einaudi, 1949.

HORKHEIMER, Max. Teoria Crítica. Buenos Aires: Amorrortu Editores, 1977. . Teoría Crítica I - Max Horkheimer. São Paulo: Perspectiva: Editora da USP, 1990.

Teoria Tradicional e Teoria Crítica. In: ;ADORNO, Theodor W. Textos Escolhidos. Coleção Os Pensadores. São Paulo: Nova Cultural, 1991.

Eclipse da Razão. São Paulo: Centauro Editora, 2000.

JAMES, W. Pragmatismo. São Paulo: Martin Claret, 2005.

KOPNIN, P. V. A dialética como lógica e teoria do conhecimento. Rio de Janeiro: Civilização Brasileira, 1978.

KOSIK, K. Dialética do concreto. 2.ed. Rio de Janeiro: Paz e Terra, 2002.

PIERCE, C. S. The fixation of belief. Popular Science Monthly, n.12, p.1-15, Nov. 1877. Illustrations of the logic of science. Disponivel em: $<$ http://www.peirce.org/writings.html>.

Deduction, induction and hypothesis. Popular Science Monthly, n.13, p. 470-482, Aug. 1878. Illustrations of the logic of science. Disponivel em: <http://www.peirce.org/writings.html>.

Comment rendre nos idées claires. Revue Philosophique de la France et de L'Étranger, n.7, p.39-57, Jan. 1879. Illustrations of the Logic of Science. Disponivel em: <http://www.peirce.org/writings.html>.

. Escritos coligidos. Seleção: Armando Mora d'Oliveira. São Paulo: Nova Cultural, 1989. (Coleção Os Pensadores).

REALE, Giovanni; ANTISERI, Dario. História da filosofia. Vol. III. São Paulo: Paulus, 1991.

VÁZQUEZ, A. S. Filosofia da práxis. 2.ed. Rio de Janeiro: Paz e Terra, 1977. 